\title{
Information Processing and Demand Response Systems Effectiveness: A Conceptual Study
}

\author{
SilpaSangeeth L.R. \\ Department of Management Studies \\ Indian Institute of Technology Madras \\ silpasangeeth@smail.iitm.ac.in
}

\author{
Saji K. Mathew \\ Department of Management Studies \\ Indian Institute of Technology Madras \\ saji@iitm.ac.in
}

\begin{abstract}
This paper studies the effectiveness of demand response (DR) programs based on information processing theory. Following information processing theory, we propose a theoretical model which examines the fit between information processing needs and information processing capacity in an energy informatics framework. We analyze nature of tasks in DR programs and classify them into generic tasks categories based on the complexity of tasks. Our model further analyzes information processing capacity of DR within an automatic metering infrastructure (AMI) system and identifies four constituents of information processing capacity. Further, we extend task-technology fit and information processing theory to posit six propositions that explore the fit between elements of information processing capacity and needs and how the fit will impact DR outcomes. Our model contributes to the information system research connecting information and utility sector to administer the effectiveness of demand response systems that ultimately enhances environment sustainability.
\end{abstract}

\section{Introduction}

Demand response (DR) programs enabled by automatic metering infrastructure (AMI) rely on data based decisions to bring a balance in the electricity demand and supply. These programs act on information by reducing consumption during peak loads or shifting these peak loads to off-peak hours. Thus, the shift towards achieving sustainability will require technological advancement in processing immense data, and information will play a major role in driving the behavioral changes in energy consumption [1].Demand response systems have gained some traction in India where the energy sector is fast expanding and accounts for $10 \%$ of the increase in global energy demand since 2000 [2]. Post electricity deregulation in India in the year 1991, smart grids and demand response systems have emerged as a potential approach to bring efficiency to the sector.

DR systems acquire, integrate and analyze data pertaining from various sources and provide information. Decision makers have to interpret and act on the information to achieve DR program outcomes. Information received as output from Business intelligence and analytics (BI\&A) in a DR system is further used by DR management to positively influence the behavior of consumers. In such a scenario, what characterize the tasks involved in DR programs? Further, AMI has the potential to supply data at different frequencies and different levels of granularity [3]. Therefore, what capacity for information processing will be required to match various tasks involved in DR systems? How do they affect DR outcomes? Our research is guided forward by these questions.

In order to encourage DR among consumers, the utility industry is having a paradigm shift from the traditional electromechanical meters to smart meters which are the main producers of large volumes of data. According to India Smart Grid Forum Report [4], 300 million smart meters will be rolled out in next 5 years, polling data at 15 minutes interval i.e. a total volume of around 30 billion meter reads per day. It is further estimated that at $1.5 \mathrm{~kb} /$ per poll, the industry has to handle roughly 5 terabytes of raw data per day. In addition to these data, there will be information flow of price updates and feedback interventions to the consumers, resulting in petabytes volume of data generation. Smart meters and other devices in the grid that monitor, control and send data to the centrally located management center forms the AMI system. Demand response system compiles the dynamic data from diverse sources of information into a logical whole [5]. The information is 
systematically synthesized to communicate among the stakeholders across the digital value chain.

As India is set for rapid and sustained growth in energy demand, a clear understanding of information processing capacity that AMI must build for DR effectiveness is crucial. The purpose of this paper is to propose a theoretical framework to understand the information processing needs and capacity to balance the supply and demand systems. Drawing on information processing view, we argue that there should be a fit between information processing needs and capacity to improve the effectiveness of demand response systems.

\section{Literature review}

In this section, we review information processing theory in IS literature and apply it to the information needs and capacity in DR systems through a conceptual model.

\subsection{Information processing theory in IS research}

Information processing theory in IS literature draws on organizational information processing theory (OIPT) proposed by Galbraith [6]. According to this theory, organizations must process information to complete different internal tasks, coordinate diverse activities and interpret the external unstable environment affecting the systems [7]. Information processing refers to the gathering, interpreting, and synthesizing information in the context of organizational decision making [8, 9]. Organizations should develop information processing mechanisms to overcome the limited capacity for an acceptable level of performance. According to organizational information processing theory, for an effective performance, there should be a match between information processing requirements of an organization and information processing capacity of the organization's structure $[9,10]$.

Previous studies on OIPT suggest organizational effectiveness is affected by the level of uncertainty. Uncertainty is defined as the difference between the information possessed by the organization and information required for completing a task [8]. In order to reduce uncertainty, organizational structure and its support systems need to be tailored to provide sufficient data for coordination and controlling activities $[7,9,11]$. Prior studies on uncertainty show that information processing increases with increase in complexity of the organizational task.
In IS literature Mason [12] reviewed Shannon's [13] mathematical theory of communication and classified information communication process into three hierarchical levels - Technical, Semantic and Influence. Bensaou and Venkatraman[14] studied the characteristics of inter-organizational relationships among five clusters by analyzing the fit between the variables of information processing needs and information processing capability constructs. Premkumar et al. [15] used "fit as matching" [10] concept to study the impact of the interaction between the processing needs and processing capabilities on procurement performance in an interorganizational supply chain management process.

\subsection{Information needs for demand response}

In the context of environmental sustainability, Watson et al. [3] proposed an integrated framework called energy informatics to study information flows in an energy system. The core idea behind this integrated framework is to combine flows in energy consumption and information systems to improve the energy efficiency. They have discussed how information forms the pivot in designing information systems (IS) to recognize the interdependencies among the functionalities of the major energy system technology elements (flow networks, sensor networks, and sensitized objects).

Energy efficiency and load management are the two main objectives of demand response programs. Energy efficiency programs are aimed at reducing the overall use of total energy, whereas load management modifies the consumption patterns through techniques like load shifting, valley filling, and peak clipping. Feuerriegel et al. [16] developed an IT artifact integrating demand response to the energy informatics framework that studied parameters like load demand, energy price, and weather forecasts affecting information systems in taking timely decisions. Later, Feuerriegel et al. [17] designed a cost-value model which incorporated relevant information and communication technology cost components in demand response system.

Information and communication technology forms the backbone of the smart grids to enable the communication and coordination of large scale spatially distributed systems for data storage and data processing [18]. Corbett [19] constructed a theoretical model using organizational information processing theory to understand the fit between the information processing requirements and information processing capabilities. Further, it was also suggested that this fit is a prerequisite for the effectiveness of 
the electricity demand management systems. However, we posit that the effectiveness of DR systems is better characterized by the fit between information processing needs and information processing capacities. Therefore, our study focuses on the understanding of information processing capacity in terms of information output from DR systems. In this work, we study the flow of information in DR systems by combining physical, technological and human resources as elements of information processing capacity.

In sum, information processing theory in the context of demand response system suggests that fit between the information processing requirements and information processing capacity would influence the effectiveness of the electricity demand management systems. However, there is a lack of clarity in what constitutes this fit to balance information processing capacity with the information processing requirements. This paper presents a theoretical model to develop understanding of the role of IS in improving the efficiency of DR systems using organizational information processing theory. We adapt concepts from Mason [12] and propose a structure for information processing capacity in a demand response system. We also use the theory of task technology fit [20] to understand characteristics of information processing needs to be based on the nature of tasks performed.

\section{Research model}

In the context of organizational information processing theory in decision making, our model elucidates two dimensions - information processing needs and information processing capacity of demand response systems in AMI. Information processing is the capability of the systems to gather, aggregate, process, exchange and distribute information.

\subsection{Information flow in AMI}

Meter data from sensors flow into the data acquisition module at every defined time interval. Semantic information integration module aggregates the assembled data with other external data to form meaningful information. The logical information is carefully extracted, transformed and analyzed using the BI\&A tools to generate knowledge about the prevailing situation. This knowledge is utilized to make wise decisions by the domain experts to bring feasible business decision outcomes. Figure 1 shows the diagrammatic representation of the information flow in automatic metering infrastructure.

\subsection{Information processing needs}

As information increases, uncertainty decreases [7]. Information processing requirements are based on each task, their characteristics, external factors that influence the task, and interdependence of the tasks [9]. The information processing needs should capture both internal and external sources of uncertainty. Therefore, the two sources of uncertainty - task complexity and environmental uncertainty determine our information processing needs.

\subsubsection{Task complexity}

The nature of the task plays an important role in determining the solution for the desired outcome. In the context of demand response systems, we review the literature and identify different tasks as: Energy billing, Service restoration, Demand response scheduling, Pricing decisions and Capacity planning. Task complexity is characterized by an increase in information load, information diversity and rate of information change [21]. As the task complexity increases there are more information processing requirements which affect the performance of the system. On the basis of sources of complexity, tasks are categorized as simple tasks, decision tasks, judgment tasks, problem tasks and fuzzy tasks [21]. Simple tasks have only a single path and one outcome, decision tasks have multiple end states, judgment tasks are characterized by conflicting interdependencies and probabilistic links, problem tasks have multiple paths to the desired outcome and fuzzy tasks are the most complex with the presence of multiple outcomes and multiple paths. Table 1 summarizes the demand response tasks and their classification based on complexity.

\subsubsection{Environmental uncertainty}

There is high uncertainty associated with predicting the outcome of functional units. The uncertainty of the environment can be understood by identifying its dimensions - complexity and dynamism $[22,23]$. Complexity deals with the degree to which the factors in the decision unit's environment are small or large in number and dynamism indicates the degree to which these factors change over time. In this study, we identify weather pattern and market price to represent the complexity dimension; and supply uncertainty, demand uncertainty and policy uncertainty to capture dynamism.

Integrating demand response to the grid will have an effect on consumers in responding to the changes 
in the price [24]. Electricity prices and weather pattern are the external environmental factors needed to design load forecasting models and to take decisions on load curtailment [17].

The amount of electricity that a retailer has to buy is determined by forecasting the demand and supply based on the historical and current electricity consumption [17, 24]. The load profiles can be used to understand the behavioral and psychological factors to find the effective ways to achieve energy efficiency [25]. Demand uncertainty is linked to the unpredictability of the electricity load usage.

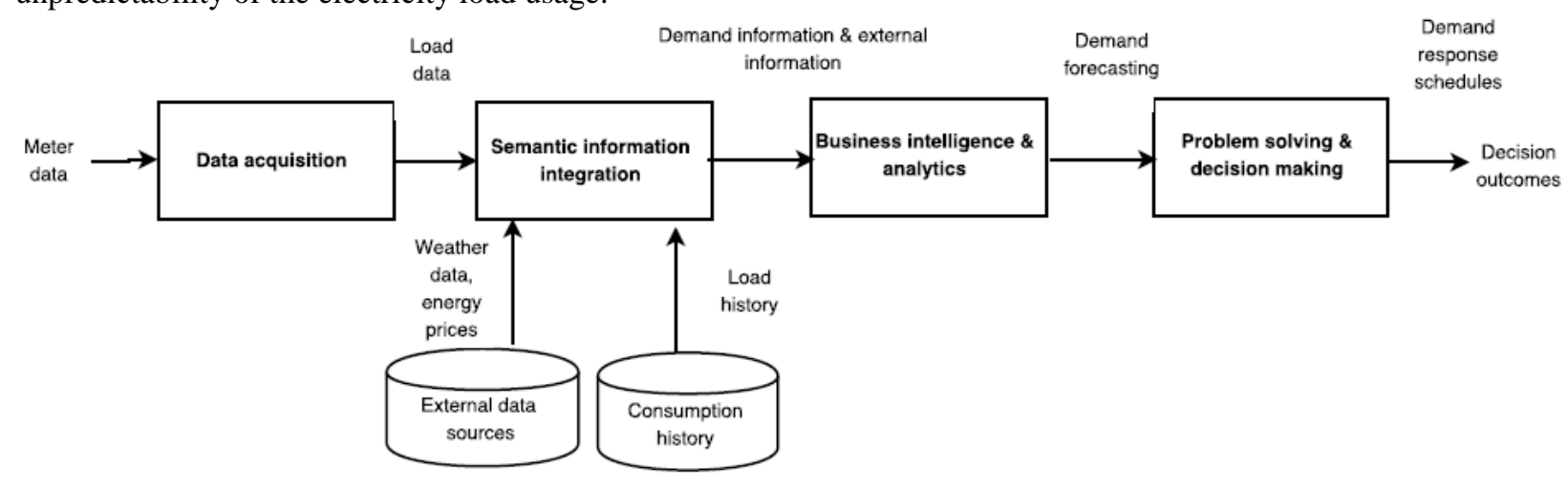

The existing electricity utilities have only oneway lines to supply the power from the generation units to meet the customer needs. Integrating renewable sources of energy to the grid, power will be generated locally at the customer end that needs to be fed to the grid to match the demand with the available supply. Supply uncertainty is the huge fluctuations in the supply of electricity due to the high volatility of intermittent resources of power like wind and solar energy.

Figure 1. Information flow in automatic metering infrastructure

Table 1.Demand response task classifications

\begin{tabular}{|c|c|c|}
\hline $\begin{array}{l}\text { Demand response } \\
\text { tasks }\end{array}$ & Nature of tasks & $\begin{array}{l}\text { Task } \\
\text { type }\end{array}$ \\
\hline Energy billing [32] & $\begin{array}{ll}\text { - } & \text { Assembling smart meter data } \\
\text { - } & \text { Aggregation of load consumption history }\end{array}$ & $\begin{array}{l}\text { Simple } \\
\text { task }\end{array}$ \\
\hline $\begin{array}{l}\text { Service restoration } \\
\text { [33] }\end{array}$ & $\begin{array}{l}\text { - } \\
\text { - }\end{array}$ & $\begin{array}{l}\text { Problem } \\
\text { task }\end{array}$ \\
\hline $\begin{array}{l}\text { Demand response } \\
\text { scheduling } \\
{[32,34,35]}\end{array}$ & $\begin{array}{l}\text { - } \text { Demographics and Socio-economic factors } \\
\text { - Analyzing consumer behavioral attitudes } \\
\text { - } \text { and consumption patterns } \\
\text { - } \text { Customer segmentation } \\
\text { - } \text { Demand shaping } \\
\text { - Recommend strategies for load curtailment } \\
\end{array}$ & $\begin{array}{l}\text { Decision } \\
\text { task }\end{array}$ \\
\hline $\begin{array}{l}\text { Pricing decisions } \\
{[32,36-38]}\end{array}$ & $\begin{array}{l}\text { - } \quad \text { Prosumer Markets } \\
\text { - } \quad \text { Multi-area load scheduling } \\
\text { - }\end{array}$ & $\begin{array}{l}\text { Judgment } \\
\text { task }\end{array}$ \\
\hline $\begin{array}{l}\text { Capacity planning } \\
{[32,39-42]}\end{array}$ & 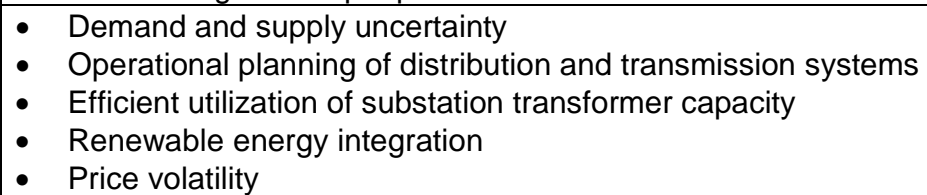 & $\begin{array}{l}\text { Judgment } \\
\text { task }\end{array}$ \\
\hline
\end{tabular}

Modernization of traditional electrical system will affect the existing policy measures. Smart grids will require huge capital investments for the expansion of the existing system. Policy makers should be able to anticipate both technological and economic changes in capacity planning and dispatching of electricity. 
The roles of new incumbents in the energy market and degree of control by energy companies in the digital value chain are still unclear. Integrating other sources of energy like renewable, that contribute to the mitigation of climatic change will need major institutional revamps in environmental policies to curb greenhouse emissions. Thus, policy uncertainty and government regulations would be important to assess the future direction of the utility industry.

\subsection{Information processing capacity}

Having identified the constituents of information processing needs in DR systems, we now identify dimensions of information processing capacity. Information flow in a demand response system in AMI constitutes four modules: (i) Data acquisition, (ii) Semantic information integration, (iii) Business intelligence and analytics, (iv) Problem solving and decision making.

\subsubsection{Data acquisition}

Smart meters can generate both high and low frequency metering data [26]. The high frequency metering data is required to be transmitted very frequently and nearly at real time for grid operations like demand forecasting or fault detection. Low frequency data is collected to provide billing information to the customers. High frequency metering data will require more information processing capacity to collect meter data from the sensitized objects and sensor networks transmitted through the flow networks. Data acquisition capacity measures the system's ability to handle the volume of data. In order to avoid information overload and to obtain timely information, it is essential to estimate the frequency of inquiry of data among the entities. With the deployment of advanced energy information and communication technologies, it is also important to study the level of information granularity to optimize a given flow network that includes all the stakeholders [3]. Data granularity identifies the most critical information needs and helps the decision makers to harness the right data from the huge volume of data. The more the data is detailed, the more amount of information has to be processed. For instance, consumers would like to know the usage data of the objects they own and as an informed user would better know how to manage their energy consumption patterns. From the suppliers' point of view, they would integrate supply and demand data to increase energy efficiency. Government as a policy maker would insist on detailed data to enable effective enforcement of energy policy. Identifying the right amount of data with respect to the stakeholders' information needs is inevitable for performance improvement.

\subsubsection{Semantic information integration}

The IS enabled information processing capacity should link and coordinate activities of interdependent functional subunits. Meter data management system (MDMS) provides storage, management, and processing of smart meter data to be used by the power system applications and services. Assembling the dynamic data from sensors, integrating the external data from heterogeneous databases, logically organizing and optimizing large amounts of data at the real time are the objectives of semantic information integration. The larger the volume of data being communicated through the network, the higher would be the ambiguity associated with the same. The quality of information is critical in complex decision-making processes [12]. Data quality of the information system is based on the following attributes - accuracy, relevance, representation and availability of data [27].

\subsubsection{Business intelligence and analytics}

Organizations collect and store a massive amount of data, but a key to derive value from data is the use of analytics [28].In energy data analytics, business intelligence and analytics provide interactive visualization, online analytical processing (OLAP), predictive analytics and data mining solutions [29, 30]. Data collected by the smart meters may be classified as conventional and new. Conventional data is the electricity consumption value. The new data pertains to the operational state of consumption such as the values of active power, reactive power, voltage, current, phase angle, power outage logs etc. The massive amount of data so gathered is processed by the supervisory control and data acquisition (SCADA) systems generating enormous volumes of information at real time. In addition to this information, DR systems use external sources like weather data and market price as an input to the forecasting models to predict the load demand. In a data rich DR system, the decisions at different spatial and temporal granularities about when, by how much, and whom to target for curtailment is guided by advanced data analytics [31]. Analyzing demand characteristics for demand shaping uses sophisticated demand modeling and prediction techniques which need demand data to be accurate and complete. This information can be utilized to design innovative 
demand response strategies and target different customer segments.

Data analytics techniques alone are not sufficient to handle different tasks. People with analytical expertise should know how to use the emerging technologies to leverage information resources. They must be expert in identifying the current business needs and be able to choose the best practices and analytical approaches to meet the needs of utility sector that derive business value. Given the complexity of uncertainty in energy systems planning, managerial skills will assist in answering ad-hoc queries and real time decisions.

\subsubsection{Problem solving and decision making}

As smart grids evolve incrementally, a number of technical and procedural challenges emerge. Data analysis enables the policy makers to identify existing gaps and design a policy that can help achieve sustainable energy efficiency. Domain expertise helps address the challenges based on the insights drawn from data analytics. The experts discover patterns and relationships from facts and use them to provide actionable information that creates value for the organization [28].These actions are in turn expected to improve energy efficiency and load management in DR.

\subsection{Energy demand response effectiveness}

DR programs ensure the prompt response of consumers to dynamic pricing. Consumption of less energy in response to high prices will reduce the cost of total electricity production and thus bring down the wholesale purchase costs in the electricity markets. Demand response programs should ensure the grid stability at real time by balancing the demand and supply despite the uncertainties in the future demand. Hence successful implementation of DR programs will bring both financial and operational benefits to the stakeholders of the grid. The electricity consumers will financially benefit through cost savings earned by regulating their demand needs in response to price based or incentive based programs. Time varying pricing plans will encourage customers to take control of their electricity prices. Incentive based programs for load management will provide grid stability and enhances its reliability. Integrating demand response to long term and short term resource planning will eventually bring financial benefits to utilities as it will reduce the capacity requirements during peak demand, driving down prices for wholesale electricity purchases. In the long run, this price reduction will be reflected on the consumers' cost saving.

\subsection{Fit - information processing needs and capacity}

Viewing through the lens of organizational information processing theory, our research model proposes the effectiveness of energy demand response systems as a fit between the information processing needs and information processing capacity in the utility. Figure 2 gives a schematic view of the model.

Zigurs and Buckland [20] have conceptualized task-technology fit based on the attributes of task complexity and their relationship to relevant dimensions of group support technology to improve the performance of group support systems. Our proposed model claims that same relationship exists between the task complexity and information processing capacity that will influence the effectiveness of energy demand response systems.

Our research model adapts organizational information processing theory to examine the fit between information processing needs and information processing capacity to study its impact on the effectiveness of energy demand response systems. The greater the task complexity, the greater is the amount of information that must be processed among decision makers in order to achieve a given level of performance [11].

P1: Task complexity with adequate information processing capacity will influence energy demand response effectiveness.

\subsection{Energy billing}

Monthly energy billing uses the load profile data collected from the smart meters installed at the consumer premises [32]. The disaggregated consumption data at the device level is assembled in the smart meters and is stored in the load history database of meter data management systems. The information processing capacity should provide 


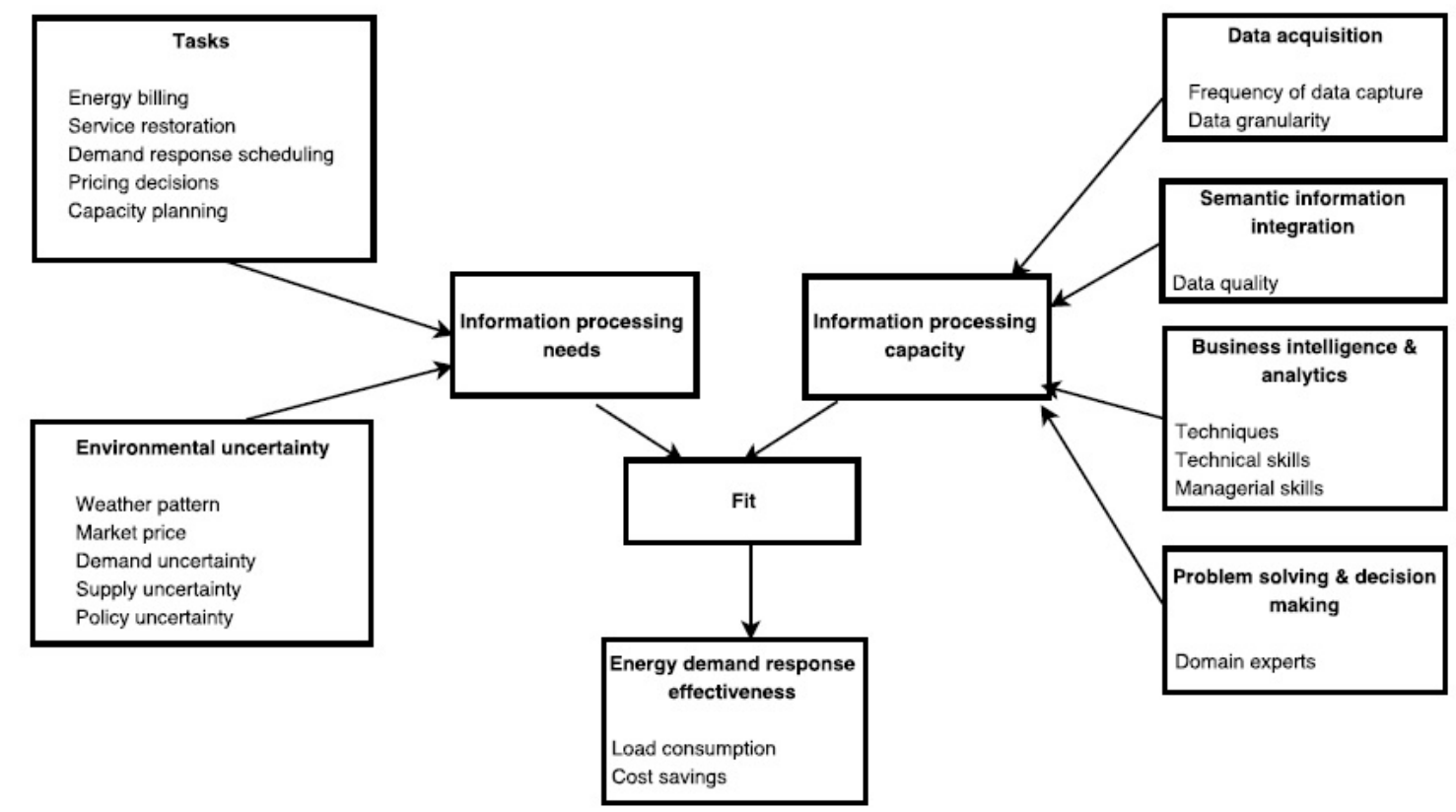

Figure 2.Proposed theoretical model

technical level support to those sensors and sensitized objects across flow network can connect with each other for data aggregation. A routine task like monthly energy billing as such is a simple task. Thus,

P2: Energy billing in the presence of data acquisition and semantic information integration will influence energy demand response effectiveness.

\subsection{Service restoration}

During emergency operating situations, reconfiguration of power transmission lines demands an increase in information load in the flow networks. An electric power system should quickly respond to disturbances and load shifts. Therefore, service restoration is a problem task wherein the optimum strategy to achieve reliable power in the face of a blackout is addressed and resolved. By issuing commands through a high-speed communication network, following the isolation of a faulted transmission line, additional capacity may be quickly made available to restore power supply [33]. Such non-routine tasks will incur an increase in information load making it essential for the data from the flow networks to be handled by elements of information processing. Accordingly,
P3: Service restoration in the presence of data acquisition, semantic integration, and business intelligence will influence energy demand response effectiveness

\subsection{Demand response scheduling}

Decision makers need to process massive amount of information in an uncertain environment to solve complex problems, as in the case of demand response scheduling. Demand uncertainty in residential consumers depends on socio-economic factors and their load usage preferences [32]. The consumption data from the smart meters can be used to characterize consumers with similar load profiles and identify the best demand response strategy to each segment to achieve the desired load curtailment [34, 35].

Analysis of consumer's consumption pattern and tracking their behavioral attitudes towards demand response programs use data mining techniques and analytics tools to evaluate information. Real-time energy monitoring and information evaluation help in load prediction and providing effective feedback to customers. Hence demand response scheduling is a decision task that is characterized by high information load and information diversity making it 
crucial for the flow networks to have good information processing support to integrate heterogeneous information sources. Hence, we propose:

P4: Demand response scheduling in the presence of data acquisition, semantic information integration and business intelligence \& analytics will influence energy demand response effectiveness

\subsection{Pricing decisions}

While different methods of making residential consumers responsive to prices or incentives have been practiced in the utility industry, the diffusion of smart meters and AMI provide a novel communication platform to better connect with the consumers. Using DR systems, distribution network operators communicate to the end-customers about the price changes in the market and provide information regarding their energy usage, encouraging them to shift their energy demand and thus reducing price volatility [36].In DR systems, it is important to predict and model how consumers shift their loads from high-priced peak hours to low-priced off peak hours to reduce their energy cost [32]. This helps the market operators to design a market clearing price mechanism that accepts complex bids from demand and supply side market players in the day-ahead market with the objective to maximize the social welfare. The real time active participation of consumers to strategically bid in the designed auction market will mitigate the spot price volatility and eventually reduce the overall cost of electricity productions [37]. In the decentralized electricity grid, prosumer adoption is more complex as it envisages information processing capacity to understand the behavior of multiple agents communicating with different households. In the prosumer era, where the consumers are informed and active, it is necessary to differentiate the prosumer markets based on the types of services and changing functional roles in the decision models of a distributed system [38]. Demand side participation will enable multi-area load scheduling where the information is exchanged among neighboring geographical regions to coordinate unit scheduling and allocate reserves among the interconnected competitive electricity markets to provide the customers with cheap and reliable power. Therefore, we have categorized pricing decisions as judgment tasks as it requires a system to combine and coordinate the interdependent tasks for information exchange for decision making. Hence, we propose,
P5: Pricing decisions in the presence of data acquisition, semantic information integration, business intelligence \& analytics and problem solving \& decision making will influence energy demand response effectiveness

\subsection{Capacity planning}

The demand response systems become more crucial when integrated with diverse distributed generations like wind energy or other renewable sources. Uncertainty in the demand and supply information will require the decision makers to evaluate and integrate diverse sources of information in making a prediction about the likelihood of some future event. Thus, capacity planning is a judgment task as it is associated with very high information load and information diversity that requires a good understanding of the problem domain to design a solution scheme. Capacity planning of existing transmission and distribution systems with demand response will provide substantial monetary savings [32, 39 - 41]. The system operators need to correctly identify the consumers to negotiate the amount of load curtailments to avoid network congestion in the load lines [42]. Capacity planning with demand response will help in reducing power outages during contingencies and guarantees power quality. Thus, it can be stated,

P6: Capacity planning in the presence of data acquisition, semantic information integration, business intelligence \& analytics and problem solving \& decision making will influence energy demand response effectiveness

\section{Discussion and Conclusion}

Transformation of the utility sector to the smart grid environment in India poses a high degree of technological challenge and calls for smart engineering solutions. Further, the current line of exploration would eventually open up new and exciting avenues for improved business practices such as dynamic, near real-time demand management, analysis of consumption patterns and behavior modeling of customers. For instance, they can use analytic techniques to determine variable pricing models and provide customized rate plans for DR target segments.

The purpose of our study is to understand the information processing needs and capacity of DR systems and their influence on DR program outcomes. Our study contributes to the body of 
knowledge pertaining to information systems in the domain of energy informatics. More specifically, our model extends task-technology fit to investigate the association between task complexities and information processing capacity and its effect on DR performance. We analyzed the characteristics of various tasks involved in DR programs and classified them into generic tasks categories based on the complexity of tasks. We further analyzed information processing capacity of DR within an AMI system and identified four elements of capacity. Further, following information processing theory, we arrived at six propositions that explore the fit between elements of information processing capacity and need and how the fit will impact DR outcomes.

A number of aspects of the present work would be appealing for a researcher and have scope for improvement. The proposed model can be enhanced by incorporating behavioral and psychological aspects of the consumers in delivering significant energy savings. Our model is conceptual in nature and requires validation by explorative field studies. Further, propositions given in the study need to be refined for hypotheses testing for future statistical generalization.

\section{References}

[1] R. Gholami, R.T. Watson, A. Molla, H. Hasan and N. Bjørn-Andersen, "Information systems solutions for environmental sustainability: How can we do more?", Journal of the Association for Information Systems, Association for Information Systems, US,2016, p.521.

[2] IEA, "India Energy Outlook" [online], Retrieved from:http://www.worldenergyoutlook.org/media/weowebsit e/2015/IndiaEnergyOutlook_WEO2015.pdf, accessed on February 2017

[3] R.T. Watson, M.C. Boudreau and A.J. Chen, "Information systems and environmentally sustainable development: energy informatics and new directions for the IS community", MIS Quarterly, Management Information Systems Research Center, US, 2010, pp.23-38.

[4] ISGF,"Advanced metering infrastructure rollout strategy for India" [online], Retrieved from:http://www.indiasmartgrid.org/reports/ISGFWhitePap eronAMIRoll-OutStrategyforIndia.pdf, accessed on August 2017

[5] Y. Simmhan, Q. Zhou and V. K. Prasanna, "Semantic Information Integration for Smart Grid Applications," Green IT: Technologies and Applications, Springer, 2011, pp. $361-80$
[6] J.R. Galbraith, "Designing complex organizations", Addison Wesley Publishing Company, 1973.

[7] R.L. Daft and R.H. Lengel, "Organizational information requirements, media richness and structural design," Management Science, Institute for Operations and the Management Sciences, US, 1986, pp.554-571.

[8] J.R Galbraith, "Organization design”, Addison Wesley Publishing Company, 1977.

[9] M.L. Tushman and D.A. Nadler, "Information processing as an integrating concept in organizational design", Academy of Management Review, Academy of Management, US, 1978, pp.613-624.

[10] N. Venkatraman and J.C. Camillus, "Exploring the concept of "fit" in strategic management", Academy of Management Review, Academy of Management, US, 1984, pp.513-525.

[11] J.R. Galbraith, "Organization design: An information processing view,” Interfaces, INFORMS, 1974, pp.28-36.

[12] R.O. Mason, "Measuring information output: A communication systems approach", Information \& Management, Elsevier, 1978, pp.219-234.

[13] C.E. Shannon and W. Weaver, "The mathematical theory of communication", Urbana, IL: Urbana University of Illinois Press, 1949.

[14] M. Bensaouand N. Venkatraman, "Configurations of interorganizational relationships: A comparison between US and Japanese automakers", Management Science, Institute for Operations and the Management Sciences, US, 1995, pp.1471-1492.

[15] G. Premkumar, K. Ramamurthy and C.S. Saunders, "Information processing view of organizations: an exploratory examination of fit in the context of interorganizational relationships", Journal of Management Information Systems, Taylor \& Francis, 2005, pp.257-294.

[16] S. Feuerriegel, P.Bodenbenner and D. Neumann, "Is more information better than less? Understanding the impact of demand response mechanisms in energy markets", in Proceedings of the $21^{\text {st }}$ European Conference on Information Systems, Association for Information Systems, Utrecht, Netherlands, 2013, p. 167-178.

[17] S. Feuerriegel, P.Bodenbenner and D. Neumann, "Value and granularity of ICT and smart meter data in demand response systems", Energy Economics, Elsevier, 2016, pp.1-10.

[18] C. Goebel, H.A. Jacobsen, V.D. Razo, C. Doblander, J. Rivera, J. Ilg, and J. Lässig, "Energy informatics-Current and future research directions," Business \&Information 
Systems Engineering, GablerVerlag, Germany, 2014, pp.25-31.

[19] J. Corbett, "Demand management in the smart grid: An information processing perspective", in Proceedings of the $17^{\text {th }}$ Americas Conference on Information Systems, Association for Information Systems, Detroit, Michigan., 2011.

[20] I. Zigurs and B.K. Buckland, "A theory of task/technology fit and group support systems effectiveness", MIS Quarterly, Management Information Systems Research Center, US, 1998, pp.313-334.

[21] D.J. Campbell, "Task complexity: A review and analysis", Academy of Management Review,Academy of Management, US, 1988, pp.40-52.

[22] R.B. Duncan, "Characteristics of organizational environments and perceived environmental uncertainty", Administrative Science Quarterly, SAGE Publications, US, 1972, pp.313-327.

[23] H.K. Downey and J.W. Slocum, "Uncertainty: Measures, research, and sources of variation," Academy of Management Journal, Academy of Management, US, 1975, pp.562-578.

[24] S. Feuerriegel and D. Neumann, "Measuring the financial impact of demand response for electricity retailers", Energy Policy, Elsevier, 2014, pp.359-368.

[25] W. Abrahamse, L. Steg, C. Vlek, and T. Rothengatter, "A review of intervention studies aimed at household energy conservation", Journal of Environmental Psychology, Elsevier, US, 2005, pp.273-291.

[26] C. Efthymiou and G. Kalogridis, "Smart grid privacy via anonymization of smart metering data", in Proceedings of the First IEEE International Conference on Smart Grid Communications, IEEE, Gaithersburg, MD, 2010, pp. 238243.

[27] R.Y. Wang and D.M. Strong, "Beyond accuracy: What data quality means to data consumers", Journal of Management Information Systems, Taylor \& Francis, 1996, pp.5-33.

[28] Hugh J. Watson, "Tutorial: Big Data Analytics: Concepts, Technologies, and Applications," Communications of the Association for Information Systems, Association for Information Systems, US, 2014.

[29] R. Bose, "Advanced analytics: opportunities and challenges", Industrial Management \& Data Systems, 2009, pp.155-172

[30] H. Chen, R.H. Chiang and V.C. Storey, "Business intelligence and analytics: From big data to big impact," MIS Quarterly, Management Information Systems Research Center, US, 2012, pp.1165-1188.
[31] Y. Simmhan, S. Aman, A. Kumbhare, R. Liu, S. Stevens, Q. Zhou and V. Prasanna, "Cloud-based software platform for big data analytics in smart grids", Computing in Science \& Engineering, IEEE, 2013, pp.38-47.

[32] M.H. Albadi, and E.F. El-Saadany, "A summary of demand response in electricity markets", Electric power systems research, Elsevier, 2008, pp.1989-1996.

[33] M.R. Kleinberg, K. Miu and H.D. Chiang, "Improving service restoration of power distribution systems through load curtailment of in-service customers", IEEE Transactions on Power Systems, 2011, pp.1110-1117.

[34] A. Albert and R. Rajagopal "Smart meter driven segmentation: What your consumption says aboutyou", IEEE Transactions on power systems, 2013, pp.4019-4030.

[35] J. Kwac, C.W. Tan, N. Sintov, J. Flora and R. Rajagopal, "Utility customer segmentation based onsmart meter data: Empirical study", in Proceedings of the IEEE International Conference on SmartGrid Communications, IEEE, 2013, pp. 720-725.

[36] S. Feuerriegel, J. Strüker and D. Neumann, "Reducing price uncertainty through demand side management", in Proceedings of the $33^{\text {rd }}$ International Conference on Information Systems, Association for Information Systems, Orlando, Florida,US, 2012.

[37] C.L. Su and D. Kirschen, "Quantifying the effect of demand response on electricity markets", IEEE Transactions on Power Systems, 2009, pp.1199-1207.

[38] Y. Parag and B.K. Sovacool, "Electricity market design for the prosumer era", Nature Energy, Nature Publishing Group, UK, 2016.

[39] M. Humayun, B.J.O. Sousa, A. Safdarian, M. Ali, M.Z. Degefa, M. Lehtonen and M. Fotuhi-Firuzabad, "Optimal capacity management of substation transformers over long-run", IEEE Transactions on Power Systems, 2016, pp.632-641.

[4o] Y. Xu, N. Li and S.H. Low, "Demand response with capacity constrained supply function bidding", IEEE Transactions on Power Systems, 2016, pp.1377-1394.

[41] J. Medina, N. Muller and I. Roytelman, "Demand response and distribution grid operations: Opportunities and challenges", IEEE Transactions on Smart Grid, 2010, pp.193-198.

[42] W. Luan, D. Sharp and S. Lancashire, "Smart grid communication network capacity planning for power utilities", in Proceedings of the IEEE PES Transmission and Distribution Conference and Exposition, IEEE, New Orleans, LA, 2010, pp. 1-4. 